\title{
Bright light and high density negative air ionisation reduced symptoms in seasonal affective disorder
}

\author{
Terman M, Terman JS, Ross DC. A controlled trial of timed bright light and negative air ionization for treatment of winter \\ depression. Arch Gen Psychiatry 1998 Oct;55:875-82.
}

\section{Question}

In patients with seasonal affective disorder (SAD), do timed bright light and negative air ionisation reduce symptoms?

\section{Design}

Randomised, morning by evening light crossover trial balanced by parallel group controls, in addition to a non-photic control (negative air ionisation), with follow up to 4 weeks.

\section{Setting}

Psychiatry department in New York, New York, USA.

\section{Patients}

158 patients between 18 and 65 years of age who were recruited through media and physician referrals with a DSM-III-R diagnosis of SAD. Exclusion criteria included other Axis I disorders, suicide attempt within the previous 3 years, and habitual sleep onset later than $1 \mathrm{am}$ or awakening later than $9 \mathrm{am} .145$ patients $(92 \%)$ completed the study.

\section{Intervention}

Patients were allocated to 6 groups for 2 consecutive treatment periods, each lasting 10-14 days. 2 parallel groups received morning treatment with negative ions. 4 groups received light treatment and were crossed over at mid point using the following sequences: morning-evening, evening-morning, morningmorning, and evening-evening (10 000 lux, $30 \mathrm{~min} / \mathrm{d}$ ). 2 groups received negative air ionisation treatment at either high density $\left(2.7 \times 10^{6}\right)$ or low density (serving as the placebo control, $1.0 \mathrm{x}$ $10^{4}$ per cubic centimeter) (high-high and low-low sequences, 30

$\mathrm{min} / \mathrm{d}$ in the morning). All treatments lasted for 20-28 days with a 1-3 week withdrawal phase.

\section{Main outcome measure}

Symptom severity assessed using the Structured Interview Guide for the Hamilton Depression Rating Scale-Seasonal Affective Disorder Version (SIGH-SAD).

\section{Main results}

Data are reported for the 124 patients who relapsed or who remained depressed during the withdrawal to ensure that clinical improvement was not caused by spontaneous remission. Patients in the light treatment and the high density negative air ionisation treatment groups improved in percentage change scores on the depression scale. Bright light in the morning or evening and high density negative ions led to clinically important relief with $>50 \%$ reduction in depressive symptoms in at least half of the patients receiving the treatment (table). Remission (defined as a SIGH-SAD score of $\leqslant 8$ after treatment) rates were higher in the morning light, evening light, and high ions groups compared with the low ions group at week 4 , and in the morning $v$ evening light comparison (table).

\section{Conclusion}

Bright light and high density negative ionisation reduced depressive symptoms in patients with seasonal affective disorder.

Source of funding: National Institute of Mental Health.

For correspondence: Dr M Terman, New York State Psychiatric Institute, 1051 Riverside Drive, Unit 50, New York, NY 10032, USA. Fax +1 2125435184.

Treatment comparisons (morning light v low density ions, evening light v low density ions, high density $v$ low density ions, and morning $v$ evening light) at week 4 for improvement in depressive symptoms and remission rates in seasonal affective disorder*

\begin{tabular}{|c|c|c|c|c|}
\hline Outcome & $\begin{array}{l}\text { Morning light, evening } \\
\text { light, high density ions }\end{array}$ & Low density ions & $R B I(95 \% C I)$ & $N N T(C I)$ \\
\hline $\begin{array}{l}\text { Improvement in depressive symptoms } \\
\text { (change in SIGH-SAD } \geqslant 50 \% \text { ) }\end{array}$ & $67 \%, 61 \%, 55 \%$ & $26 \%, 26 \%, 26 \%$ & $\begin{array}{l}153 \%(29 \text { to } 479), 131 \% \text { (17 to } 430) \text {, } \\
109 \%\end{array}$ & $\begin{array}{l}3 \text { (2 to } 8), 3 \text { ( } 2 \text { to } 13) \text {, } \\
\text { not significant }\end{array}$ \\
\hline Remission (SIGH-SAD $\leqslant 8$ ) & $56 \%, 30 \%, 40 \%$ & $5 \%, 5 \%, 5 \%$ & $\begin{array}{l}972 \%(122 \text { to } 6014), 478 \% \text { ( } 15 \text { to } 3266) \\
\quad 660 \%(45 \text { to } 4394)\end{array}$ & $\begin{array}{l}2(1 \text { to } 4), 4(3 \text { to } 30), \\
\quad 3(2 \text { to } 11)\end{array}$ \\
\hline Outcome & Morning light & Evening light & $R B I(C I)$ & $N N T(C I)$ \\
\hline Remission (SIGH-SAD $\leqslant 8$ ) & $56 \%$ & $30 \%$ & $85 \%(12$ to 214$)$ & $4(3$ to 21$)$ \\
\hline
\end{tabular}

*Data provided by the author; SIGH-SAD = Structured Interview Guide for the Hamilton Depression Rating Scale-Seasonal Affective Disorder Version. Other abbreviations defined in glossary; RBI, NNT, and CI calculated from data provided by author.

\section{Commentary}

In general, the treatment of winter depression (or $\mathrm{SAD}$ ) is similar to that of other forms of affective disorder except that bright light exposure has been recommended as the first line treatment option (the administration of visible light producing the intensity of at least 2500 lux towards the face). Indoors, at home, the intensity of light measured in front of the eyes of a standing person is typically $\leqslant 100$ lux, and 300 to 500 lux at the workplace. Outdoors, the level of illumination varies greatly by latitude, season, time of day, and local weather conditions, ranging from about $\leqslant 2000$ lux on a cloudy winter day to $\geqslant 10000$ lux in direct sunshine. A previous overview of controlled trials with 332 patients showed that light of 2500 lux in 2 hour daily morning sessions for 1 week improved $67 \%$ of patients with mild, and $40 \%$ with moderate to severe episodes of winter depression. ${ }^{1}$ Recently, the use of higher intensities (up to 10000 lux) and shorter exposures (down to half an hour) has been reported to yield equally good response rates. Designs of bright light trials have been compromised, however, by a lack of adequate control for placebo and blinding.

The studies by Terman $e t a l$ and Lewy $e t$ al overcome some of these design problems and confirm earlier data which show that bright light treatment is effective and well tolerated in patients with winter depression. The study by Terman et al, together with the results from another recent study, ${ }^{2}$ gives evidence that morning bright light treatment has an antidepres(continued on page 88) 


\title{
Bright morning light reduced depressive symptoms in seasonal affective disorder
}

\author{
Lewy AJ, Bauer VK, Cutler NL, et al. Morning vs evening light treatment of patients with winter depression. Arch Gen Psychiatry \\ 1998 Oct;55:890-6.
}

\section{Question}

In patients with seasonal affective disorder (SAD), is morning or evening light more effective in reducing symptoms?

\section{Design}

Randomised, crossover trial with follow up to end of treatment.

\section{Setting}

Sleep and Mood Disorders Laboratory in Portland, Oregon, USA.

\section{Patients}

56 patients between 25 and 61 years of age who were recruited through media and referrals from health professionals with a $D S M-I I I-R$ diagnosis of $\mathrm{SAD}$ and a score of $\geqslant 20$ on the Structured Interview Guide for the Hamilton Depression Rating Scale-Seasonal Affective Disorder Version (SIGH-SAD). Exclusion criteria included poor physical health, ideas or attempts of suicide, use of psychotropic medication, and other Axis I-III disorders. 5 patients did not complete the study. 52 matched controls with no notable medical or psychiatric problems also participated. 3 controls did not complete the study.

\section{Intervention}

After a baseline assessment period patients were allocated to bright light at either $6-8$ am or 7-9 pm for 2 weeks. After 1 week of withdrawal from light treatment, patients were crossed over to the alternate light schedule.

\section{Main outcome measures}

Symptom severity assessed using the SIGH-SAD and dim light melatonin onsets.

\section{Main results}

During the course of treatment, SIGH-SAD scores for patients in the morning light group decreased twice as much as scores for patients in the evening light group. Remission (defined as $\geqslant 50 \%$ decrease in SIGH-SAD ratings to a score after treatment of $\leqslant 14$ ) occurred in 19 patients receiving morning light compared with 3 patients receiving evening light (table). Morning light advanced the dim light melatonin onset and evening light delayed it in both patients and control participants. Patients were delayed compared with control participants at all assessment points of the study.

\section{Conclusion}

Bright morning light reduced depressive symptoms in patients with seasonal affective disorder.

Morning light v evening light in patients with seasonal affective disorder (treatment duration 2 wk)*

\begin{tabular}{lllll}
\hline Outcome & $\begin{array}{l}\text { Morning } \\
\text { light }\end{array}$ & $\begin{array}{l}\text { Evening } \\
\text { light }\end{array}$ & RBI (95\% CI) & NNT (CI) \\
\hline Remission & $37 \%$ & $6 \%$ & $533 \%(119$ to 1831) & 4 (3 to 7) \\
\hline
\end{tabular}

*Abbreviations defined in glossary; RBI, NNT, and CI calculated from data in article.

Sources of funding: Public Health Service, Bethesda, MD, and the National Alliance for Research on Schizophrenia and Depression, Chicago, IL.

For correspondence: Dr A J Lewy, Sleep and Mood Disorders Laboratory, Department of Psychiatry, L-469, Oregon Health Sciences University, 3181 SW Sam Jackson Park Road, Portland, OR 97201 3098, USA. Fax +15034945329 . (commentary continued from page 87) sant effect that is statistically beyond its placebo effect. The benefit of light over placebo is in producing substantially more full remissions. Both studies also pull together conflicting research findings and show that bright light treatment is more effective when given in the morning than in the evening. Another, as yet preliminary, finding reported in the study by Terman et al is the antidepressant effect of high density negative air ionisation.

Why is bright light treatment effective in winter depression? Fixed phase delays in the timing of the circadian clock are suggested to have a key role in winter depression. According to this hypothesis, the efficacy of morning bright light treatment is related to the corrective phase advances. Recent data show, however, that the circadian cycle appears to be more elastic in patients with winter depression compared with healthy people, deviating more from 24 hours and peaking at less regular times. ${ }^{3}$ Patients with winter depression tend to show an abnormal degree of phase advance during bright light treatment, ${ }^{4}$ although the necessity of phase advances for clinical efficacy have now been questioned.

There is some evidence that suggests that the resetting of the circadian clock is worsened by the decreasing photoperiod or exposure to cold weather at high latitudes, and with aging. There may also be separate time givers regulating waking up and falling asleep. Information of the direction (decreasing or increasing) and velocity of change of the photoperiod is being transformed into the production of melatonin. This signal might then entrain the 2 timegivers discordantly, predisposing to winter depression, for example, because of irregularities in the circadian clockwork.

The mechanism aside, the studies by Terman et al and Lewy et al provide sound evidence that most patients with winter depression will benefit most from bright light exposure immediately on awakening. In selected patients, the evening bright light treatment can be a preferred alternative. The practice guidelines for the intensity and duration of bright light exposure to optimise the treatment outcome still await further investigation. The study by Terman et al also provides evidence that high density negative air ionisation may have a marked antidepressant effect. This finding awaits replication in future investigations.

Timo Partonen, MD, PhD National Public Health Institute Helsinki, Finland

1 Terman M, Terman JS, Ouitkin FM, et al. Neuropsychopharmacology 1989;2:1-22. Neuropsychopharmacology 1989;2:1-22.
Eastman CI, Young MA, Fogg LF, et al. Arch Gen Eastman CI, Young MA, Fo
Psychiatry 1998;55:883-9.

Psychiatry 1998;55:883-9. Teicher MH, Glod CA, Magn
Psychiatry 1997;54:124-30. Psychiatry 1997;54:124-30. 4 Thompson C, Childs PA, Martin NJ, et al. Br J Psychiatry 1997;170:431-5. 